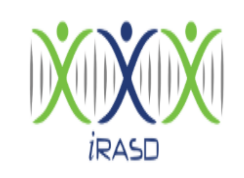

Pakistan Journal of Humanities and Social Sciences

Volume 9, Number 3, 2021, Pages 399-411

SCIENCES (PJHSS)

IRASD

Journal Homepage:

https://journals. internationalrasd.org/index.php/pjhss

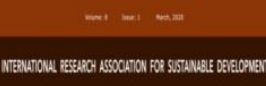

\title{
Relevancy and Effectiveness of In-Service Training with Professional Needs of University Teachers in Curriculum Development and Instruction
}

Jam Muhammad Zafar ${ }^{1}$, Muhammad Asif ${ }^{2}$, Muhammad Akram³, Muhammad Aslam ${ }^{4}$

1 Assistant Professor, Department of Humanities and Social Sciences, Khwaja Fareed University of Engineering and Information Technology, Rahim Yar Khan, Pakistan. Email: dr.zafar@kfueit.edu.pk

2 PhD Scholar, Department of Humanities and Social Sciences, Khwaja Fareed University of Engineering and Information Technology, Rahim Yar Khan, Pakistan. Email: muasif@numl.edu.pk

3 Assistant Professor, Department of Humanities and Social Sciences, Khwaja Fareed University of Engineering and Information Technology, Rahim Yar Khan, Pakistan. Email: muhammadakramw@gmail.com

4 Ph.D. Scholar, Department of Humanities and Social Sciences, Khwaja Fareed University of Engineering and Information Technology, Rahim Yar Khan, Pakistan. Email: aslammalik71@yahoo.com

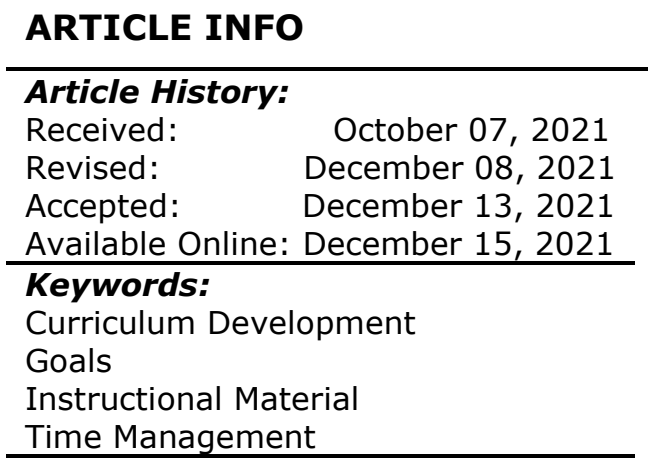

\section{ABSTRACT}

The major purpose of the study was to critically analyze the relevancy and effectiveness of the training contents and process of the workshop, to assess the training needs of university teachers in terms of conceptualizing new meaning and scope of curriculum development. The population of the study consisted of thirty-nine teachers from different departments of the Khawaja Fareed University of Engineering and Information Technology Rahim Yar Khan and resource person. Pre and Post tests were developed as a research tool. A pre-test was to be delivered to the trainees for assessing their previous knowledge about curriculum development. At the end of the workshop, a post-test was conducted to evaluate the outcomes of the workshop. Researchers also observed the resource persons' role, participants' performance, and instructional material, time management, venue, and refreshment. The collected data through pre-test and post-test was filtered and analyzed critically. In the light of the analysis of the research study, it was found that trainees of the workshop gained enough knowledge about the concepts, models, roles, global trends in the 21st century, principles, and main factors of curriculum development. It was concluded that the workshop was effective and healthy practice for the participants in the perspectives of curriculum development at the university level.

(c) 2021 The Authors, Published by iRASD. This is an Open Access Article under the Creative Common Attribution Non-Commercial 4.0

Corresponding Author's Email: muasif@numl.edu.pk

\section{Introduction}

The efficiency and effectiveness of a training program can be judged better through the evaluation process. The process of evaluation is the only key to explore the significance of a training program and to suggest appropriate strategies for betterment. Rao (2005) described that the training program remains worthless if the process of evaluation is skipped. To organize, plan and execute a training program, different physical, financial and human resources are required. Taylor (2003) described that in a training program, the process of evaluation should include the utilization of available resources. The evaluation is an important component to organize an in-service teacher training program. The cost-efficiency and feedback to organize a seminar, workshop and in-service training program in future are examined through the process of evaluation. Iqbal (2011) discussed that managers of training program know through the evaluation process, to what extent objectives have been achieved.

Curriculum is the central part of teaching and learning process. Preparation of study programs, instructional methods, learning resources, lesson planning, assessment mechanism 
and even teacher education programs are the components of curriculum. According to De Coninck, C. (2008.) the process of curriculum development is concerned with educators, experts, policymakers, and government officials have a significant impact on communities' progress and prosperity. Curriculum is now considered as the central part of daily life more than ever before, and the responsibility of society as a whole. Today curriculum development highlights both a strategic process challenge as well as a policy challenge.

Higher education emphasized an important area, especially curriculum development. The curriculum provides desirable experiences. The coordinated activities are activated and made through choices of learning experiences in process of curriculum development. Goals, learners, foundations and design of curriculum are basic components of the process of curriculum development Rasheed (2000). Curriculum development consists of all major factors related to the concept, process, role, global trends, selection, analysis and organization. In a nutshell, curriculum development indicates key areas of activity that educationists and experts have to follow when developing the curriculum of a specific level (Qureshi, 2007).

Joseph, P. B. (2011) opined that cultures of Curriculum (2nd edition). New York, NY: Routledge. The term 'curriculum' signified a course of studies followed by a pupil in a teaching institution. Presently, it means, generally speaking, the contract between society, the state and educational professionals with regard to the educational activities that learners should undergo during a certain phase of their lives to learn something desirable. Standard dictionaries define curriculum as a course of study offered by an academic institution. According to Joseph (2011), curriculum is the formal and informal content and process by which learners gain knowledge and understanding, develop skills, and alter attitudes, appreciations, and values under the auspices of an academic institution. In other words, curriculum can be defined as the total experience. From this viewpoint, curriculum is not only the content selected and delivered, but also the planned and unplanned activities in which individuals participate as students (Slattery, 2006).

In educational literature, in short, the word curriculum has been defined as: Curriculum is such permanent subjects as grammar, reading, logic, rhetoric, mathematics, and the greatest books of the Western world that embody essential knowledge; curriculum is those subjects that are most useful for living in contemporary society; curriculum is all planned learning for which the institution is responsible; curriculum is all the experiences learners have under the guidance of the institution; curriculum is the totality of learning experiences provided to students so that they can attain general skills and knowledge at a variety of learning sites and curriculum is a structured series of intended learning outcomes (Kelley, 2009).

Accordng to Khawja (2009) for enhancing the quality of education at University level there was an excessive need of a training program to make university teachers more effective and professional. For this purpose training named "Master Training for Faculty Professional Development Program (MT FPDP)" was conducted at Khawaja Fareed University of Engineering and Information Technology. Qureshi, M., (2007) described that main purpose of the training was to enhance the competencies of teachers and their professional development. The training was conducted by National Academy of Higher Education (NAHE). The training was of different modules from Higher Education Commission one of which was curriculum development and instruction. Therefore researcher analyze the relevancy and effectiveness of the training contents and process of the workshop, to assess the training needs of university teachers in terms of conceptualizing new meaning and scope of curriculum development. The objectives of the study were:

- To critically analyze the relevancy and effectiveness of the training contents and process of the workshop

- To assess the training needs of university teachers in terms of re-conceptualizing the new meaning of curriculum development

- To formulate recommendations for improvement of the future training programs of higher education teachers

The Research questions of the study were: 
- How can the relevancy and effectiveness of the training contents and process of the workshop be analyzed?

- What were the training needs of university teachers in terms of re-conceptualizing the new meaning of curriculum development?

\section{Research Methodology}

The researcher participated in a short training workshop and observed its whole mechanism, content, interactive sessions, activities and video conference. The researcher exchanged feelings with participants as well as resource persons of the workshop during the whole session and assessed participants prior knowledge and expectations to learn from the module. The researcher filled an observation format to examine resource persons' role, participants' performance, venue, instructional material, time management and refreshment. The population of the study was consisted on all the faculty members of Khawaja Fareed University of Engineering and Information Technology Rahim Yar Khan. The sample of the study consisted of thirty-nine teachers from different departments of Khawaja Fareed University of Engineering and Information Technology Rahim Yar Khan and resource person.

The study was qualitative and descriptive in nature. Pre and Post tests were designed as a research tool. Pre and Post was validated by pilot study. Researcher conducted a pilot study for this purpose Pre and Post was presented to experts they give their opinion about the Pre and Post changes were made according to expert opinions and then Pre and Post were finalized. Reliability of Pre and Post was checked by Cronbach's alpha which was found $0.73 \mathrm{An}$ observation checklist was developed to collect the data about curriculum development at higher education level focusing upon;

- Theme-1: Concept of syllabus, course and curriculum

- Theme-2: Role of curriculum in the educational perspective of Pakistan

- Theme-3: Trends of curriculum design and development in the $21^{\text {st }}$ Century

- Theme-4: Models of curriculum development

- Theme-5: Qualities of a good curriculum designer/developer

- Theme-6: Major factors of curriculum development

- Theme-7: Effective elements of curriculum development

- Suggestions for future

Above mentioned themes was formed from HEC Training Modules.

\subsection{Data Collection}

A pre-test was administered to the trainees for assessing their previous knowledge about curriculum development and their expectations. The researcher personally collected data during the workshop and critically observed its mechanism, content, lecturers, activities, video conferences and exchanged views with resource persons. The researcher observed the resource persons' role, participants' performance, instructional material, time management, venue and refreshment. At the end of the session, post-test was conducted to evaluate the outcomes of the workshop.

\section{Data Analysis}

The collected data was analyzed critically by using qualitative data analysis techniques. The whole data was divided and highlighted the codes as per relevance to the objectives of the study. The codes were further merged into the themes. Each theme was analyzed, interpreted and described to extract findings of the study. After the qualitative data was quantified chats was formed. With commence of the workshop session on curriculum development, a pre-test was administered to the trainees of the workshop.

To analyze the previous knowledge of the participants they filled the open-ended questionnaire which was consisted of such items: the concept of curriculum, differentiation among syllabus, course, educational program and curriculum, the role of curriculum in cultural perspectives, global trends of curriculum development in the $21^{\text {st }}$ century, principles of selection of curriculum, expectations from this training workshop with reference to curriculum development. 
Figure 1: Concept of Curriculum

Concept of curriculum (pre test)

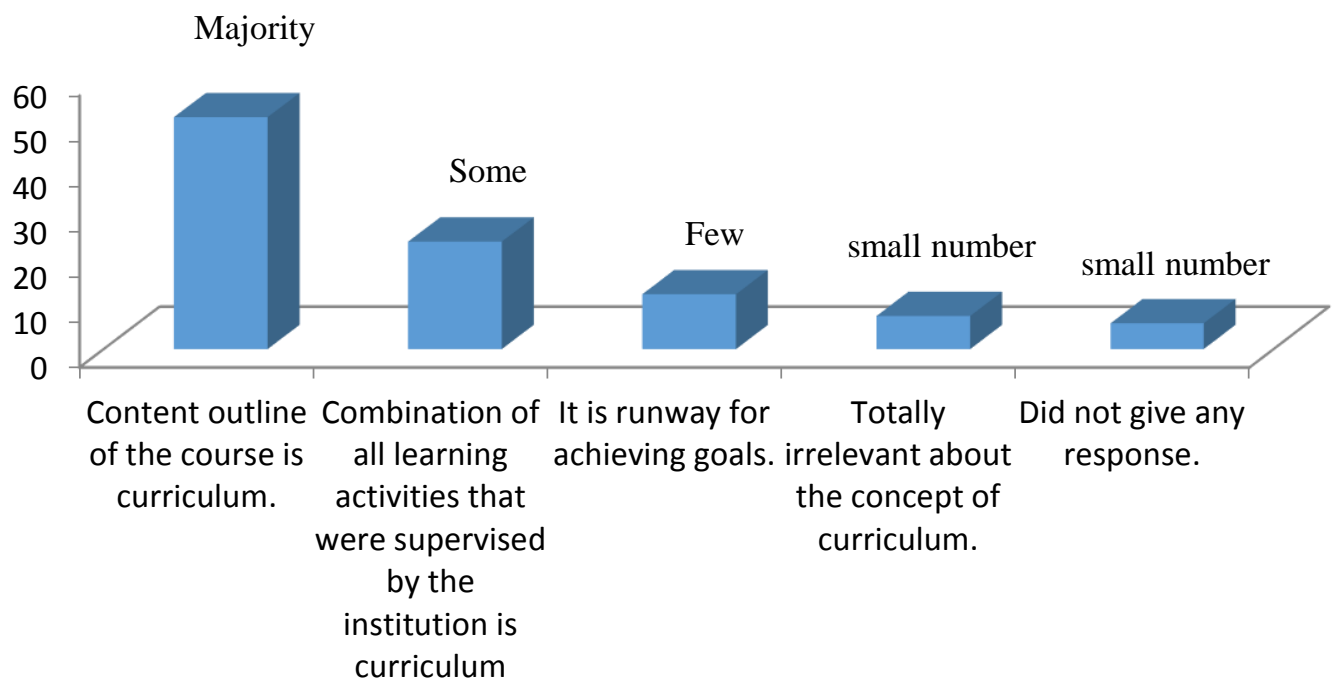

Source: Self-created chart based on data collected through pre-test and post-test

Trainees stated different ideas about the concept of curriculum such as a roadmap of the course outline, a combination of all learning activities, a runway for achieving goals. It seemed that participants were not clear about the concept of curriculum. The majority of the respondents said; a content outline of the course is a curriculum. Some of them were of the opinion that a combination of all learning activities that were supervised by the institution is curriculum. Few trainees described that it is a runway for achieving goals. A few respondents answered totally irrelevant about the concept of curriculum. Some of them did not give any response. In the light of pre-test analysis, it is revealed that there was ambiguity about the concept of curriculum among the majority of the participants. However, a small number of respondents had a clear concept about the conception of the curriculum.

\section{Figure 2: Concept of Curriculum (Post test)}

\section{Concept of curriculum (post test)}

Majority

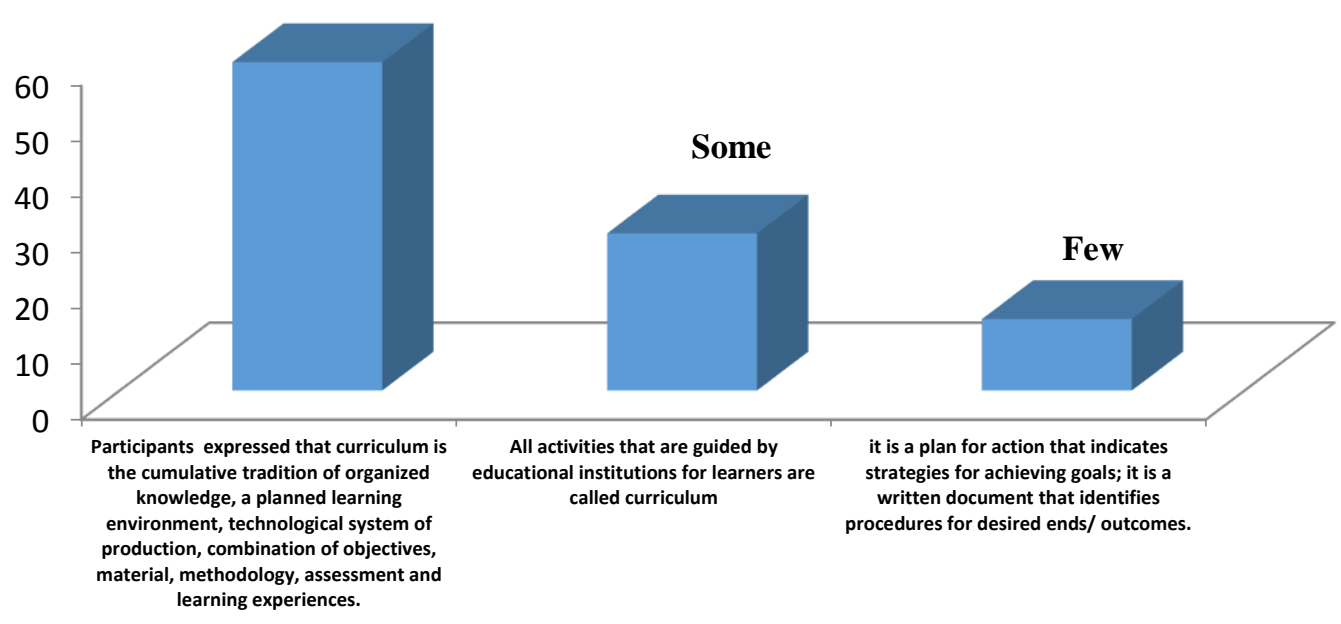

Source: Self-created chart based on data collected through pre-test and post-test

At the end of the workshop, post-test was delivered to the participants for assessing the learning outcomes of the training workshop. The majority of the participants shared their ideas clearly about the concept of curriculum. They expressed that curriculum is the cumulative tradition of organized knowledge, a planned learning environment, a technological 
system of production, a combination of objectives, material, methodology, assessment and learning experiences. Some respondents said that all activities that are guided by educational institutions for learners are called curriculum. A few stated their views in this form; it is a plan for action that indicates strategies for achieving goals; it is a written document that identifies procedures for desired ends/ outcomes. It was concluded that workshop activities improve the concept of trainees about curriculum. They had a better understanding than previous knowledge. The workshop modified their ideas, theories, and views about the concept of curriculum. All these consequences were due to the good performance of the module deliverer and master trainers.

\section{Figure 3: Differentiate, syllabus, course, educational program and curriculum}

$$
\text { Differeatiate, syllabus, course, educational program \& curriculum(pre test) }
$$

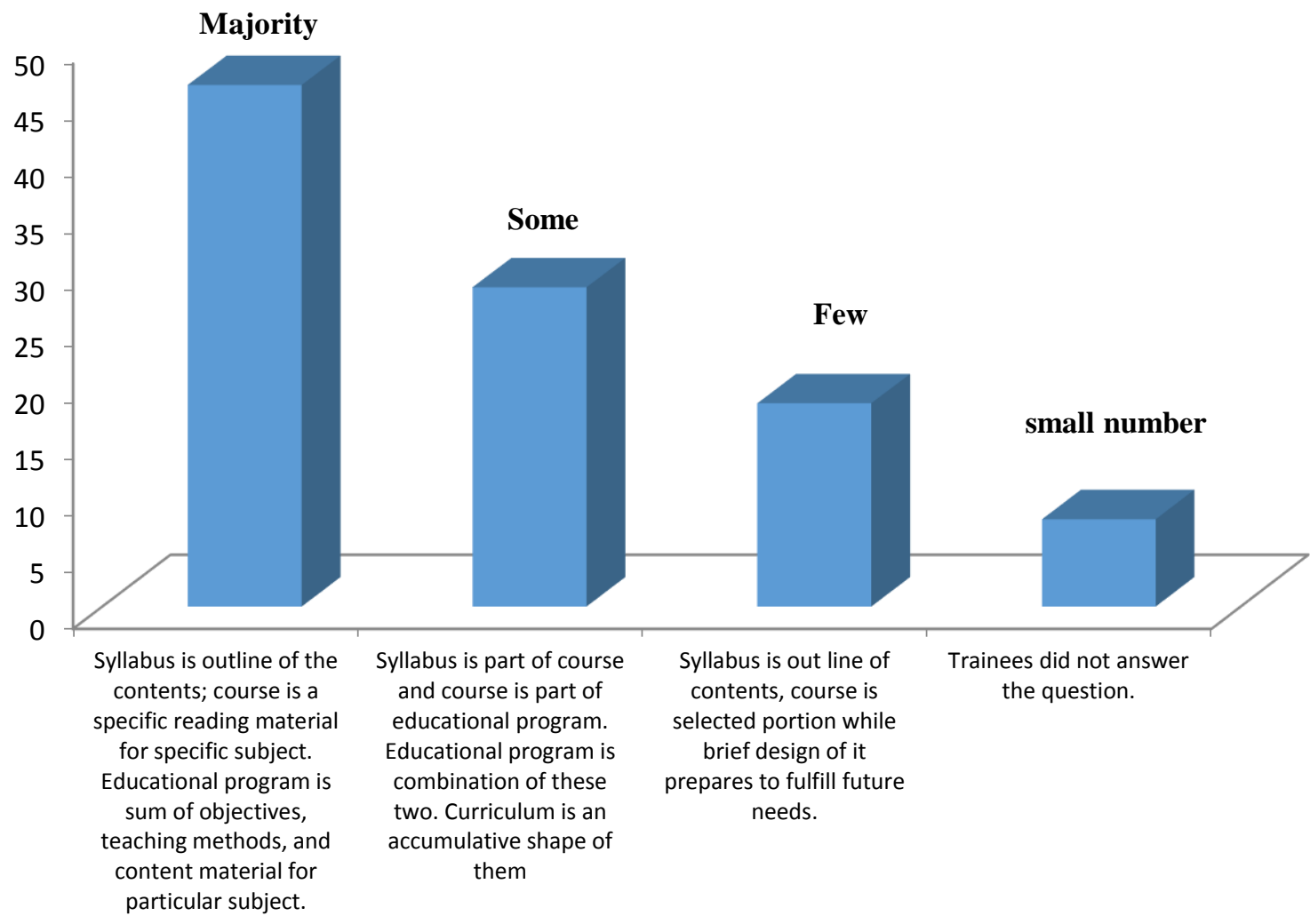

Source: Self-created chart based on data collected through pre-test and post-test

Participants of the workshop had verities of ideas about the differentiation, syllabus, course, educational program, and curriculum. The majority of the respondents said that syllabus is an outline of the contents; the course is specific reading material for a specific subject. An educational program is a sum of objectives, teaching methods, and content material for a particular subject. Some of them described that the syllabus is the part of course and the course is the part of an educational program. The educational program is the combination of these two. Curriculum is an accumulative shape of them. A few participants expressed their ideas such as; the syllabus is an outline of contents; the course is selected portion while the brief design of it prepares to fulfill future needs. A small number of trainees did not answer the question. It is concluded that most participants could not differentiate concepts of the syllabus, course, educational program and curriculum. However, a few participants explained the differences between these four concepts more clearly.

At the end of the workshop, most of the participants narrated their views that the syllabus is the outline sketch of different topics and activities included in specific subjects. The course is the outline sketch of different ways, which are adapted to achieve specific goals. The educational program means all guidance of the institution and curriculum means the formal and informal contents and processes by which learners gain knowledge and understanding, develop skills and alter attitude appropriation and values under the supervision of the institution. A few of them expressed their views that the syllabus is that details of specific 
topics included in particular subject at any level. The course is the outline sketch of different ways that enable the students to respect the social values taught through the course of any specific subject; an educational program means all the daily routine activities like assembly, time table education work, sports, educational trips, debates and guidance. Curriculum means all the learning activities which are planned and guided by the institutions whether these are carried on in groups or individually, inside or outside the institutions. It was concluded that at the end of the workshop, trainees gained enough knowledge about the differentiation between syllabus, course, educational program and curriculum when compared to the result of the pretest.

\section{Figure 4: Differentiate, Syllabus, Course, Educational Program and Curriculum}

\section{Differentiate, syllabus, course, educational program \& curriculum (post test)}

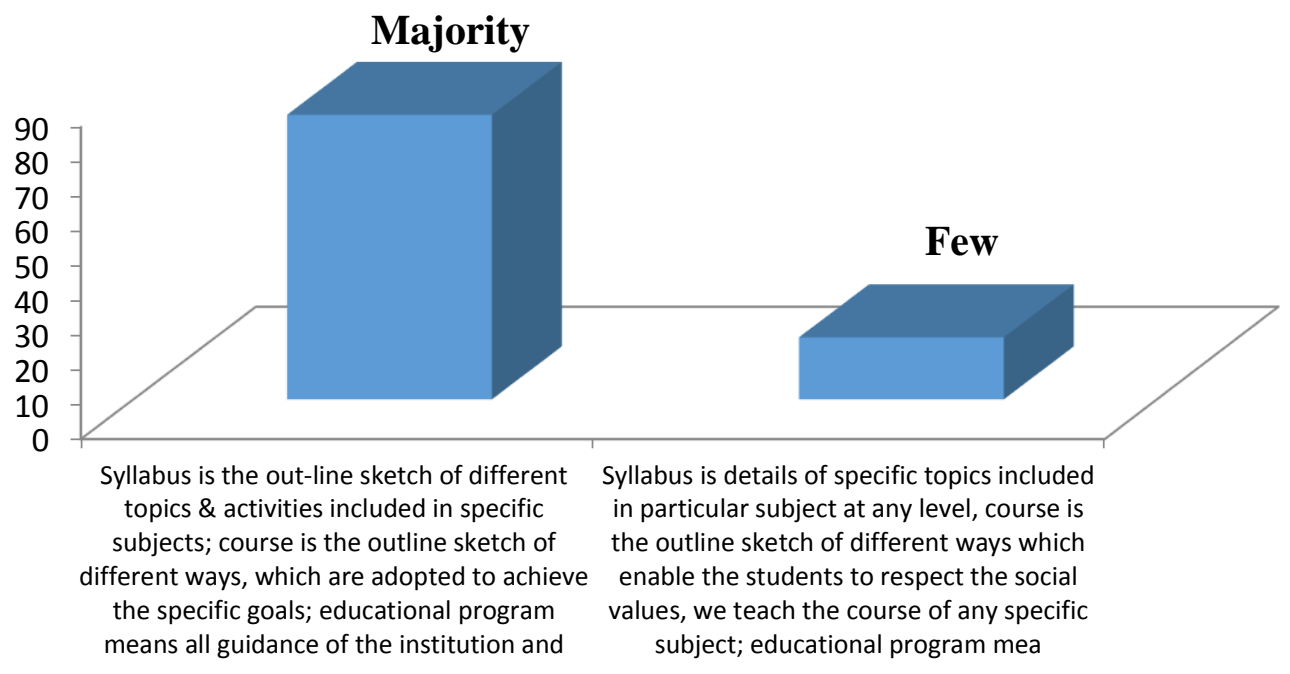

Source: Self-created chart based on data collected through pre-test and post-test

Figure 5: Role of the Curriculum in Cultural perspectives of Pakistan

Role of curriculum in cultural perspectives of Pakistan (pre test)

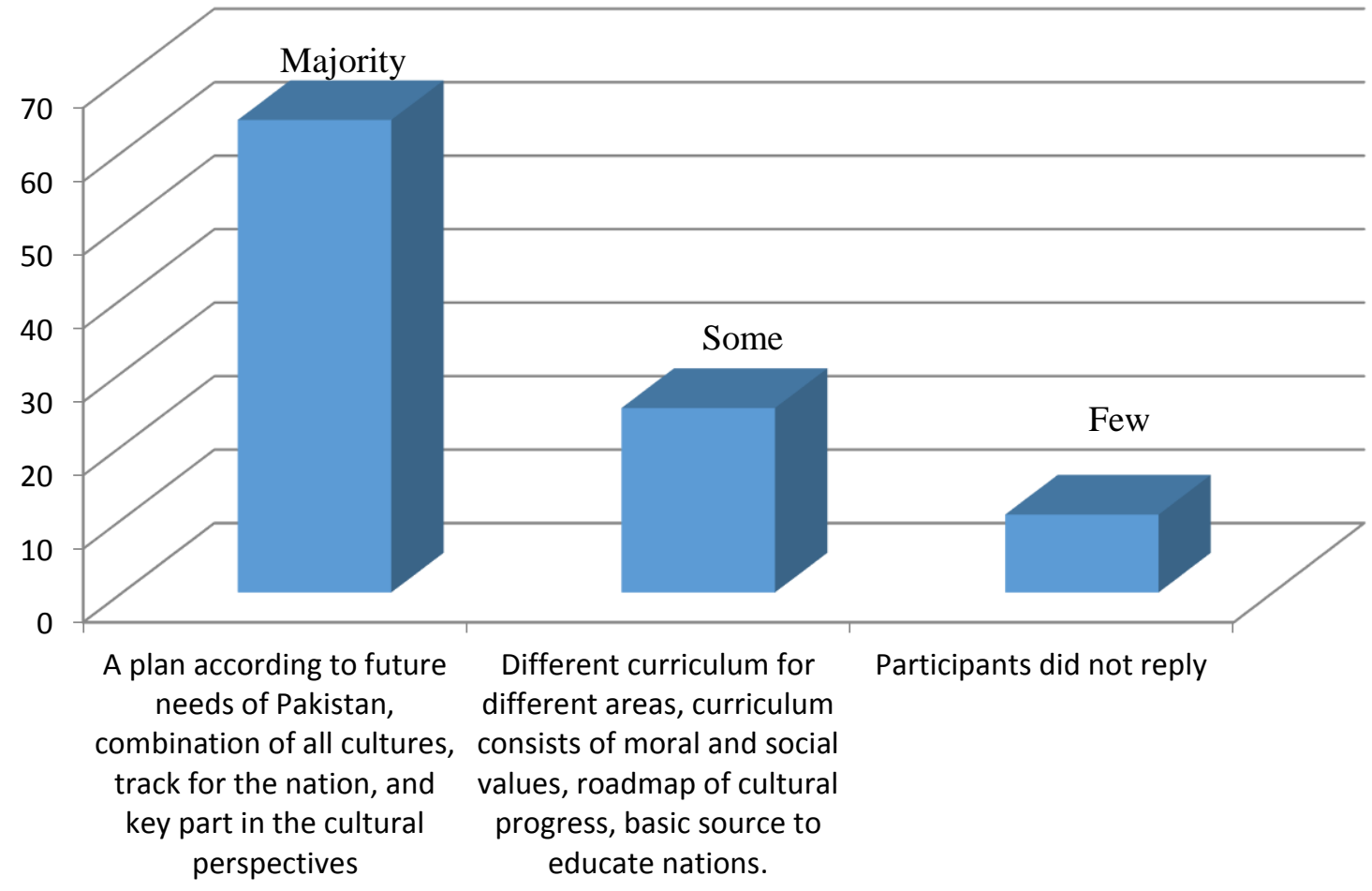

Source: Self-created chart based on data collected through pre-test and post-test 
In response to the third question, the role of curriculum in cultural perspectives of Pakistan: most of the participants were of the view that a plan should be according to future needs of Pakistan, a combination of all cultures, track for the nation, and a key part in the cultural perspectives. A few trainees said that curriculum should vary according to the areas. They added that the curriculum consisted of moral and social values, a roadmap of cultural progress, basic source to educate nations. Some of the participants did not reply. It seemed that the majority of the respondents had no clear idea about the role of curriculum in the cultural perspectives of Pakistan. A small number of participants expressed comprehensive ideas about this question.

\section{Figure 6: Role of Curriculum in Cultural Perspective}

\section{Role of curriculum in cultural perspective of Pakistan ( post test)}

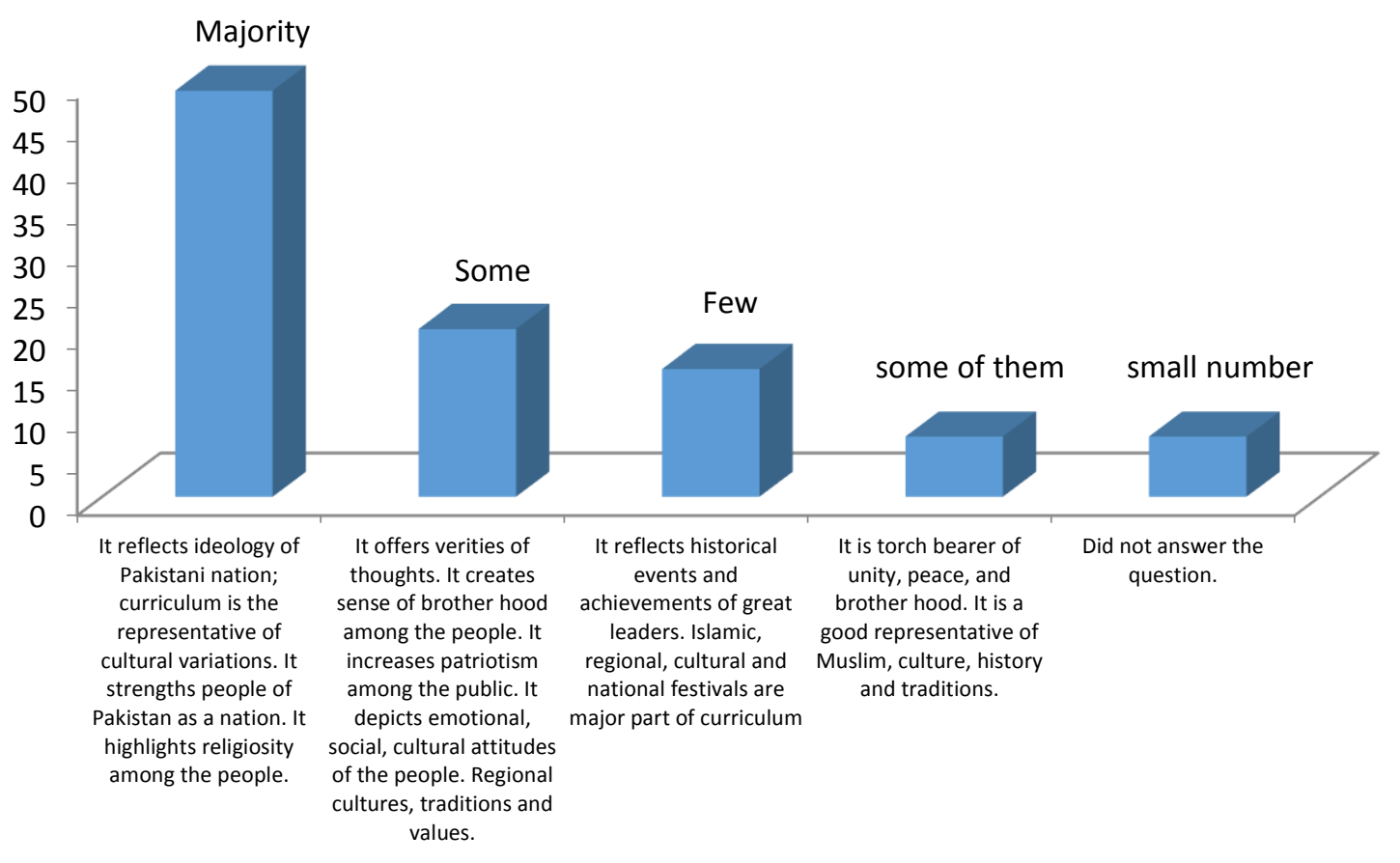

Source: Self-created chart based on data collected through pre-test and post-test

At the end of the workshop, respondents expressed their ideas more comprehensively than the pre-test results about the role of curriculum in the cultural perspectives of Pakistan. Majority of the respondents stated such as: it reflects the ideology of Pakistani nation; curriculum is the representative of cultural variations; it strengthens people of Pakistan as a nation. It highlights religiosity among people; it develops integration among people; it depicts regional traditions. A few participants narrated their views like this: it offers verities of thoughts; it creates sense of brother hood among people; it increases patriotism among the public; it depicts emotional, social, cultural attitudes of the people; presentation of the cultural diversity is also major function of curriculum; regional cultures, traditions and values are also integral parts of curriculum and depiction of historical background of the country. Some of the participants stated: curriculum reflects historical events and achievements of great leaders; Islamic, regional, cultural and national festivals are also major parts of the curriculum. A small number of participants explained it as a torch-bearer of unity, peace, and brother hood; a good representative of Muslim's culture, history and traditions. Few trainees did not answer the question. It was concluded that the concept of trainees about the role of curriculum in the cultural perspectives of Pakistan was very clear as compared to pre-test.

Majority of the participants stated their views about this question in such a way: curriculum is designed for global needs, student's cultural needs, market oriented and society centered; it must be practical less theoretical; it must be according to modern era; it should be skilled and activity based. A few of the participants said: curriculum must be precise and accurate; it should be according to the cultural and the moral values; it must be established on the scientific basis. Some of the participants viewed that representation of all aspects of life must be essential for a comprehensive curriculum. A small number of participants had no clear 
idea and some of them did not give any answer. Collectively it seemed that participants of the workshop had a lot of ideas but they were not exact, accurate and comprehensive.

\section{Figure 7: Global Trends of curriculum in $21^{\text {st }}$ Century}

Global trends of curriculum in 21st centuary (pre test)

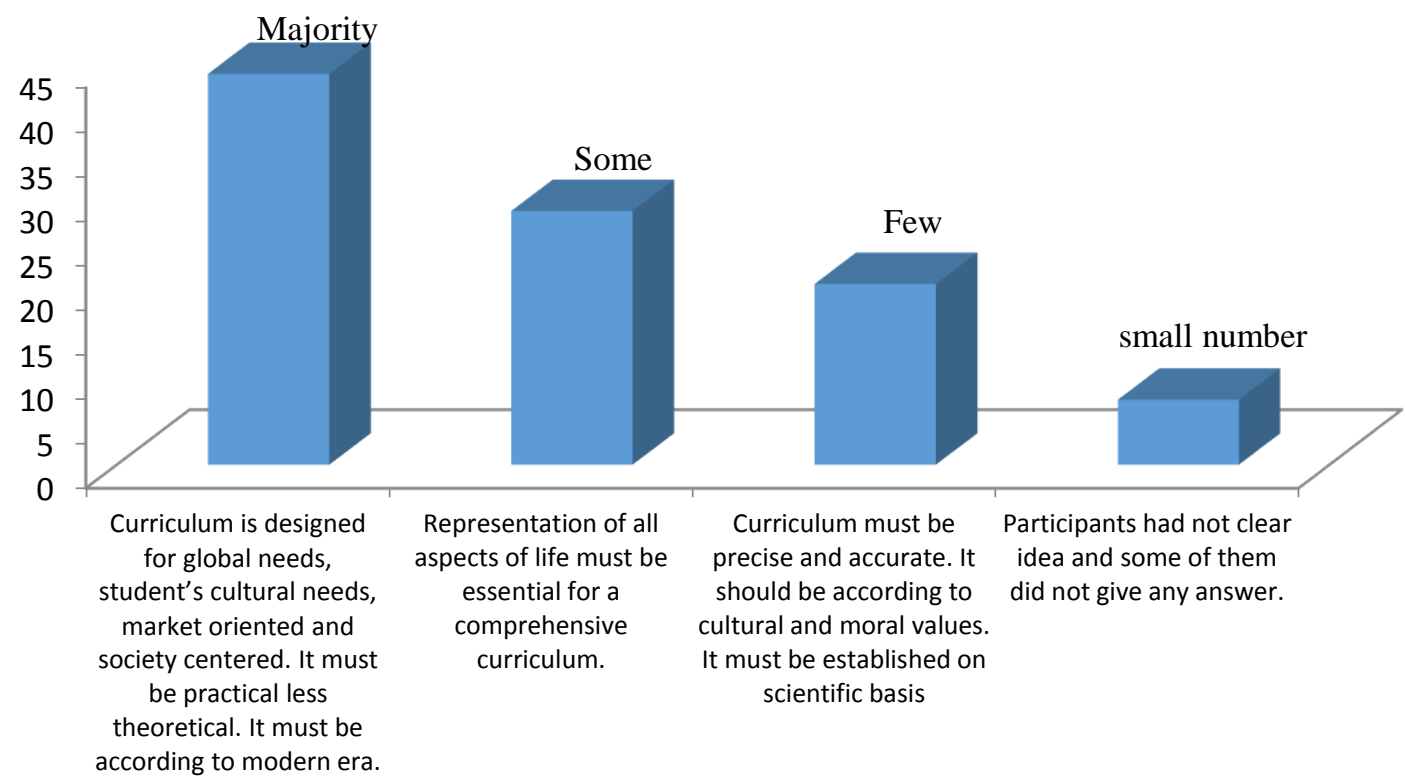

Source: Self-created chart based on data collected through pre-test and post-test

\section{Figure 8: Global Trends of Curriculum}

Global trends of curriculum in 21st century (post test)

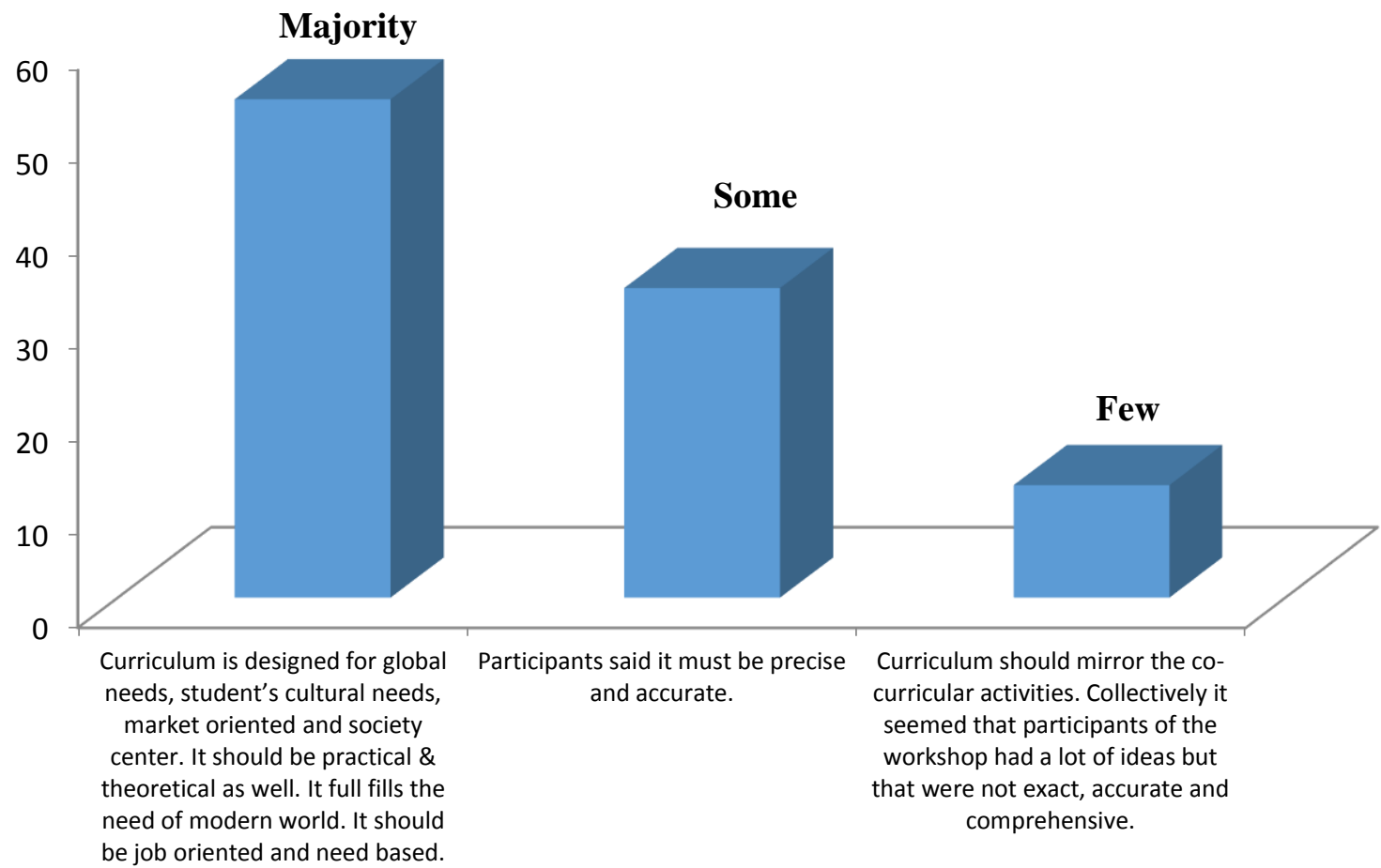

Source: Self-created chart based on data collected through pre-test and post-test

At the end of the workshop, majority of the participants stated their views about this question in such a way: curriculum is designed for global needs, students' cultural needs, market oriented and society center; mostly, it should be practical as well as theoretical; it 
fulfills the need of modern world; it should be the job oriented and need based. A few of the participants said: curriculum must be precise and accurate. A small number of participants expressed their views that curriculum should mirror the co-curricular activities. Collectively, it seemed that participants of the workshop had a lot of ideas but they were not exact, accurate and comprehensive. It was concluded, even at the end of the workshop, the trainees could not gain clear idea about the global trends of curriculum in the $21^{\text {st }}$ century in the post-test.

\section{Figure 9: Principles of selection of curriculum}

Principles of selection of curriculum (pre test)

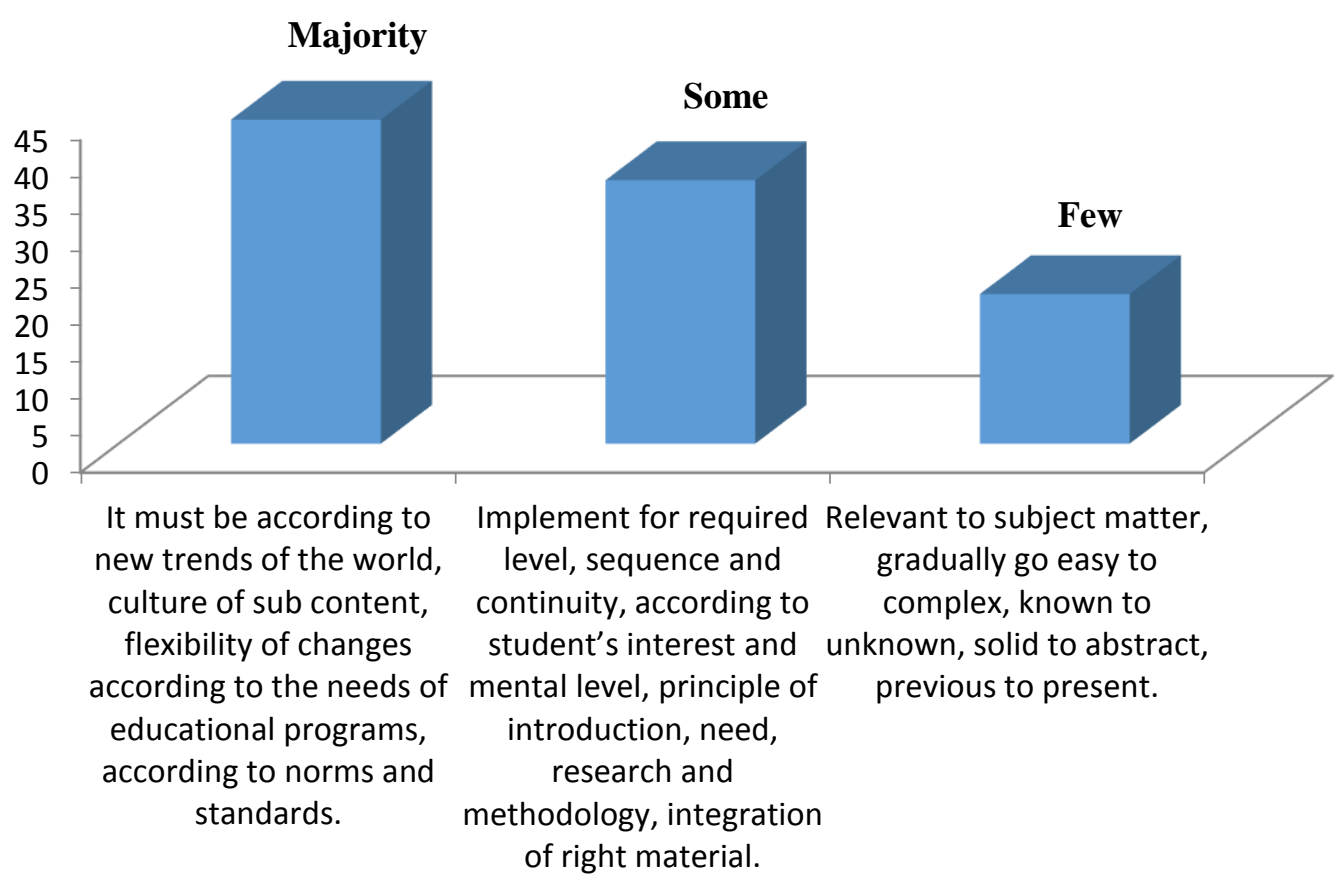

Source: Self-created chart based on data collected through pre-test and post-test

A large number of participants stated their views about this question as following: curriculum must be according to new trends of the world, the culture of sub content, flexibility of changes according to the needs of educational programs, according to norms and standards, meeting the national needs. A few of the trainees were unclear about how curriculum should be selected. They were confused about the implementation of curriculum at required level, sequence of content and continuity of ideas; they were not sure of whether it should be according to student's interest and mental level or not; they were also lacking in understanding of principle of introduction of curriculum, its needs, research and methodology, and integration of right material. Some of the respondents opined that it must be relevant to subject matter, gradually go easy to complex, known to unknown, solid to abstract, previous to present. A small number did not give their ideas. A few persons could understand the real meaning of the question while most of participants beat about the bush.

At the end of the workshop, majority of the participants stated that curriculum should be based on the prescribed principles such as balance, rationality, consistency, flexibility, practicality and responsibility. A large number of trainees expressed their views that curriculum should include the elements of design such as objectives, learning experiences, content selection and evaluation. A few of the trainees narrated that it must contain strategies for dealing with curriculum inputs from the society, the individual learning theory and knowledge. A small number of participants viewed that it should be according to student's level, represent objectives, present information in sequence according to the need of time, be helpful in methodology and suggest evaluation process. At the end of the workshop, it was concluded that the trainees had become so much clear about the principal of the selection of curriculum as compared to their previous knowledge.

Majority of the participants opined that the purposes of school educational experiences, organizational experiences, evaluation purposes, diagnoses of needs, formulation of objectives and organization of contents selection of learning experiences are according to existing 
materials are the major factors of curriculum development. A few participants expressed their views such as formulation of aims, goals and objectives. Classification of different domains, designing of curriculum and curriculum implementation are major factors of curriculum development. A small number of participants explained: formulation of objectives, selection of contents on the basis of objectives, selection and application of methodology and experiences according to content selection and evaluation procedure as a whole are the important factors of the curriculum development. A few participants described: curriculum determines goals, and specific objectives; selection of contents and creation of the design and development of implementation plans of the curriculum are the vital components of curriculum development. It seemed that the ideas of the participants had become clearer because of the workshop efforts. The researcher observed that the presentation of the module leader, activities of the trainees and learning environment of the curriculum development session proved fruitful.

\section{Figure 10: Principles of Selection of Curriculum}

Principles of selection of curriculum (post test)

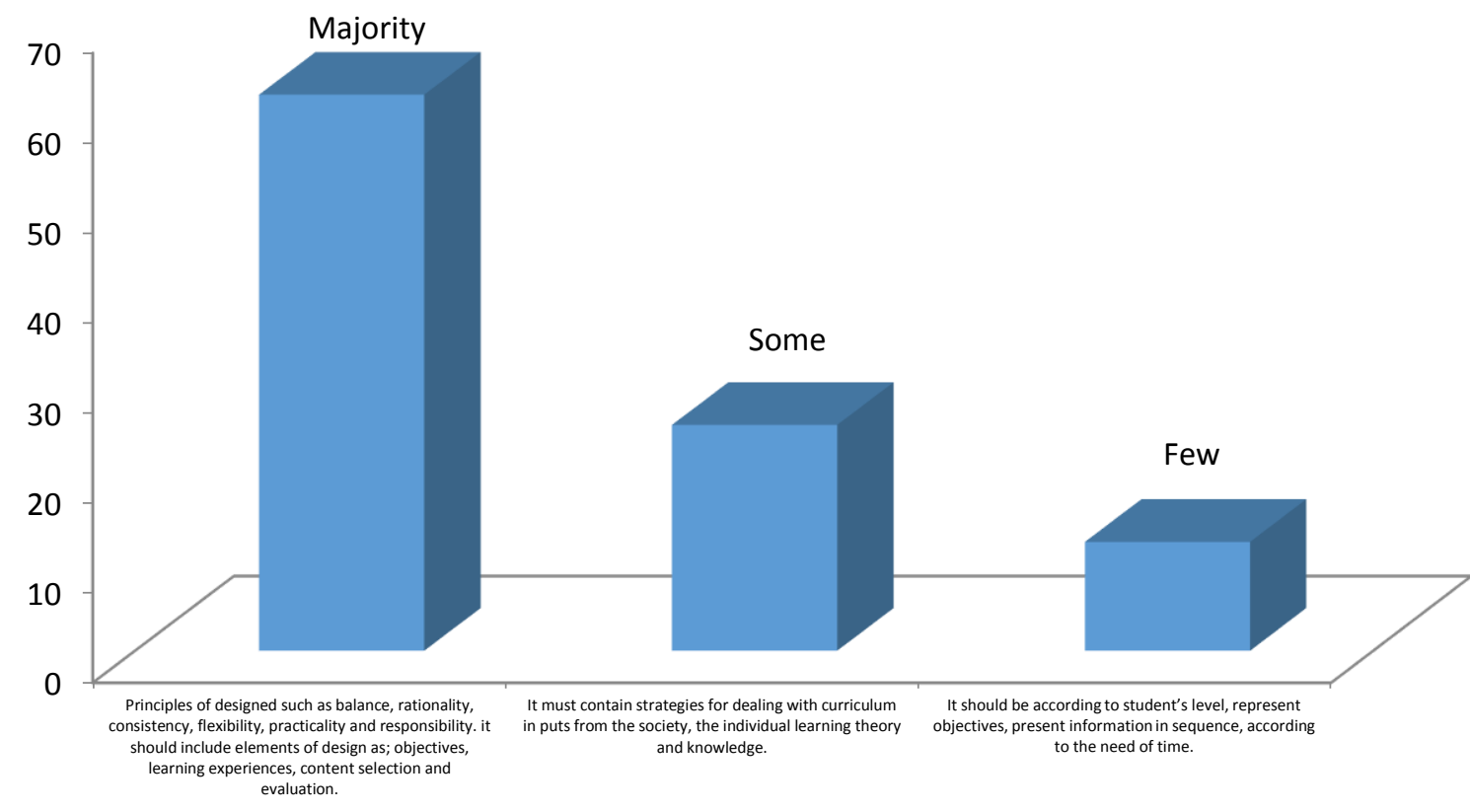

Source: Self-created chart based on data collected through pre-test and post-test

Figure 11: Important factors of curriculum

Imporatnt factors of curriculum

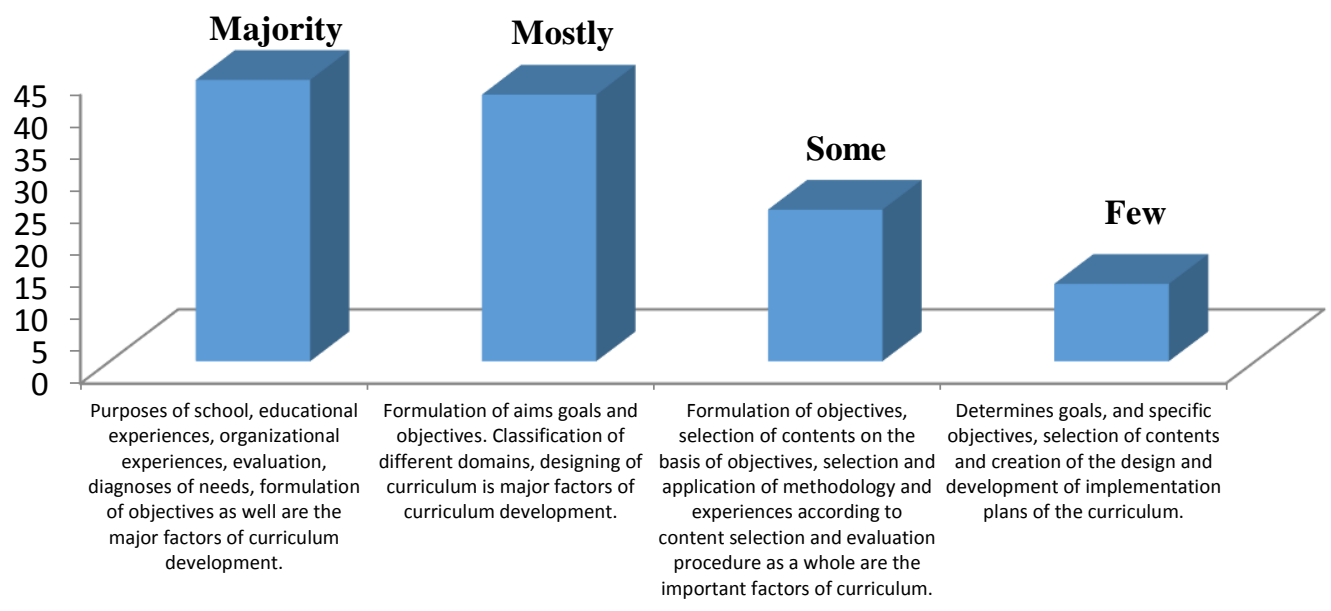

Source: Self-created based on data collected through pre-test and post-test 
The majority of the participants stated their ideas thus: surveying the situation, assessing the needs, identifying the issues, defining the problems, and recalling the accepted aims are the important elements of curriculum development. A few of the trainees also opined: making proposals, preparing the designing organization and organizing workforce are also part of curriculum development. Some of the participants stated: supervising the planning process and utilizing the products of planning also include curriculum development process. A small number of learners said: designing the evaluation sources, the conceptualization of curriculum designing, and curriculum legitimization are also a vital part of curriculum development. A few of the participant expressed their views thus: curriculum maintenance planning and the alternative and developing the learning scenarios include curriculum development process.

\section{Figure 12: Effective elements of curriculum development}

\section{Effective element of curriculum development (pre test)}

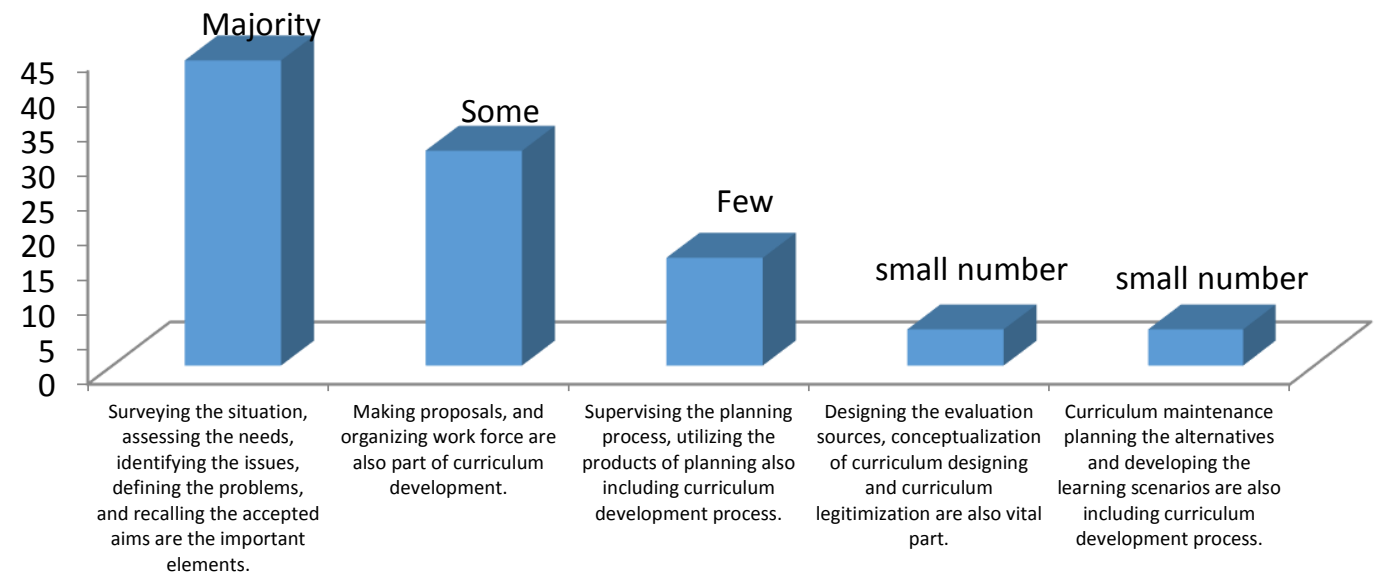

Source: Self-created chart based on data collected through pre-test and post-test

\section{Figure 13: Effective Element of Curriculum Development}

\section{Effective element of curriculum development (post test)}

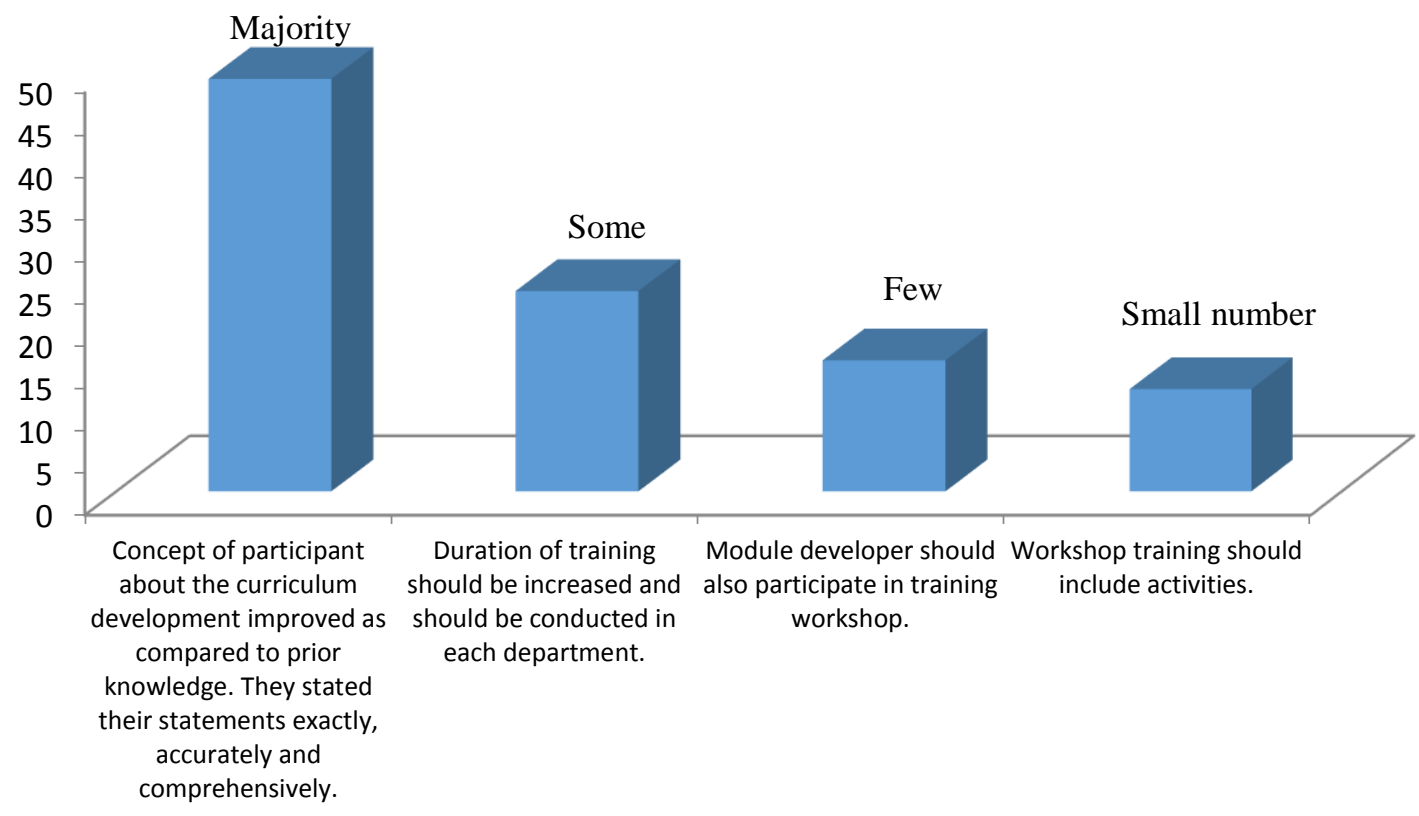

Source: Self-created chart based on data collected through pre-test and post-test

In the light of analysis of the post-test, it was concluded that the concept of the participants about curriculum development improved as compared to prior knowledge. They stated their statements exactly, accurately and comprehensively. In the light of the suggestions given by the participants, it was recommended that duration of training should be increased and should be conducted in each department. Some of them viewed that module 
developer should also participate in training workshop. A few participants expressed their views that workshop training should include activities.

\section{Conclusions and Policy Implications}

In the light of the results of the pre-test, it was found that participants of the workshop had misconception about the concept of the curriculum. Their ideas were not clear about the curriculum in the beginning of the workshop. The data revealed that trainees of the workshop had very limited knowledge and understanding about the role of curriculum development in educational institutes. The data further depicted that it was very difficult for the participants to perceive and imagine the emerging global trends of curriculum development. It was also depicted that majority of the participants had no exact idea about the principles of curriculum development, because they did not answer the question. It was also observed that during the training, the facilitators used the deduction method and asked about the principles of curriculum development and participants answered one by one. The resource person also assigned different activities to the participants of the workshop. It was also observed that trainees had unclear and mixed notions of curriculum development principles, qualities, trends and roles. The resource person assigned presentations on qualities and traits of a good curriculum designer. The resource person presented different curriculum development theories and models.

In the light of the results of the post-test conducted at the end of the training session, it was found that the reaction, deconstruction and reconstruction of new concepts, meaning and understanding about the curriculum was an interesting process of the workshop. Overall, the training session proved motivating and interesting to learn the new ideas and their application. The diversity of participants' i.e. assistant professors, lecturers, teaching assistants and internees had different needs. The diversity of subjects' i.e. basic sciences, social sciences, languages and art teachers showed different needs and consequences of the implementation of the workshop.

In the light of opinions/views of the trainees, they had fear of lack of support and facilitation from the concerned department and institutes regarding implementing the instructions of the workshop. It was also found that the participants would feel challenged and insecure if failed or produced bad results in case of non-implementation of the training recommendations. In short, the workshop seemed very successful and effective for the professional development of university and college teachers. Participants were satisfied with the environment, quality and variety of refreshments. Officials from HEC and university management frequently monitored and visited the workshop. It was concluded that participants of the workshop learned new concepts, roles, and global trends in the 21st century, principles of syllabus, course and curriculum design models of curriculum development, main factors of curriculum design and development at the university level. It was also concluded that the workshop proved effective, helpful, and professional activity for the participants to enhance their capabilities and expertise about curriculum development. It was also concluded that module leaders made a significant contribution to improve the trainees understanding of curriculum development. It was concluded that different sessions and activities proved very much effective and relevant to the needs of the workshop.

In the light of conclusion of the study following recommendations are given:

- There must bea regular mechanism of university teachers training.

- Refresher courses must be compulsory for every faculty member because of emerging trends and issues at higher education.

- There must be regular, appropriate and need based professional development opportunities for in-service university teachers.

- University teachers must have separate training sessions as per their subject need and teaching requirements.

- There must be separate professional development programs for teachers of social as well as natural sciences.

- It is recommended that duration of workshop must be extended to two to three months.

- Module writers should visit the workshop when the concerned module will present. 


\section{References}

De Coninck, C. (2008.). Core affairs: Flanders, Belgium: Case studies basic education in Europe.

Glatthorn A., (2006) Curriculum Leadership, Development and Implementation. New Delhi, Lundon: Sage Publications

Iqbal, M. (2011). Education in Pakistan: Developmental Milestones. Karachi: Paramount Publishing Enterprise.

Joseph, P. B. (2011). Cultures of Curriculum ( $2^{\text {nd }}$ edition). New York, NY: Routledge.

Kelly A.V., (2009). The Curriculum: Theory and Practice: Sage Publications. London

Khawja, I., (2009) Module on Curriculum and Assessment, Iqra University Quetta.

Ornstein A. \& Hunkins F., (1993). Curriculum Foundations Principles and Theory. Allyn \& Bacon: Prentice Hall. Boston

Qureshi M., (2006) Relevancy of NAHE Teacher Training program With Professional Need of Participants: M.Phil. Theses, IUB

Rao V.K (2005). Principles of Curriculum, New Dehli, A.P.H Publishing Corporation.

Rasheed, M. (2000). Allied Material of Curriculum Development and Instruction, AIOU Islamabad

Slattey P., (2006). Curriculum Development in the Post modern Era. Routledge, Taylor \& Francis Group: New York.

Taylor, P. (2003). How to Design a Training Course - a guide to participatory curriculum development. London: VSO/Continuum, Source: http://www.google.com, dated 25-072020. 